\title{
Detection of American Foulbrood Disease in the Apiaries of Duhok Province, Kurdistan Region, Iraq
}

\author{
Zahra Naeef Ayoub ${ }^{1}$, Ali Yahya Saeed ${ }^{2}$, Jerome Vandame ${ }^{3}$ \\ ${ }^{1}$ Department of Plant Protection, Facaulty of Agriculture and Forestry, University of Duhok, Kurdistan Region, \\ Iraq \\ ${ }^{2}$ Department of Biology, Faculty of Science, University of Duhok, Kurdistan Region, Iraq \\ ${ }^{3}$ International European Cooperation and Development organization (iecd), France
}

\begin{abstract}
American foulbrood disease is one of the most devastating infectious bacterial disease affecting the larval stage of the honey bee Apis mellifera caused by Paenibacillus larvae and occurs throughout the world. No data are available on this disease in the bees of the area, therefore this is the first study carried out in order to detect the disease in the suspected bee colonies. A total of 80 samples of suspected bee combs were collected from apiaries of different districts of Duhok province and analyzed bacteriologically. Paenibacillus larvae was found in $13(16.2 \%)$ samples among 80 suspected bee comb samples collected from different districts in which 5 from 7 districts were infected. Conclusion: American foulbrood disease is widespread in the bee colonies of the area.
\end{abstract}

Key words:American Foulbrood Disease, Apiaries

\section{Introduction}

American Foulbrood disease is one of the most devastating bacterial diseases of the honey bees caused by Gram positive, spore forming bacilli called Paenibacillus larvae subsp. Larvae which affects and kills the honey bee larvae [1]. American Foulbrood disease is classified on list B of the Office International de Epiozootic (OIE), the world organization for animal health. List B diseases are those diseases which have significant impact on the socio-economic and/or public health of the countries as well as international trade of animals and animal products [2]. The disease can be easily spread among bee colonies through contaminated bees, beekeeping equipment, pollen and honey [3] but the most common way of disease spreading among bee colonies is by combs containing the remains of infected brood. Contaminated wax by spores of Paenibacilluslarvae, which is used in the production of combs foundation, can also spread the disease [4]. AFB can be diagnosed on the basis of their clinical symptoms such as ropiness detected by the matchstick test and mottled or spotty appearance of the broodcomb , but similar symptoms may also occur with other bee diseases, therefore definitive diagnosis requires laboratory investigations conducting on the pathological materials [5].

No data are available on the American Foulbrood disease in the bee colonies of Kurdistan Region of Iraq and beekeepers have no awareness about it although clinical symptoms are highly suggestive of the disease, therefore this is the first study to be carried out on the laboratory diagnosis of this disease in the apiaries of Duhok province.

\section{Sampling}

\section{Materials and Methods}

A total of 80 samples of suspected brood combs $(15 \mathrm{~cm} \mathrm{X} 10 \mathrm{~cm}$ pieces) were collected from April to the end of October, 2013 from different apiaries of Duhok province. All samples were collected in the sterile plastic containers using sterile disposable surgical blades, then labeled and transported in the cooling box to the Microbiology laboratory/ Department of Biology/ Faculty of Science/ University of Duhok for microbiological analysis.

\section{Gross pathological symptoms of the collected samples}

Samples of infected honey bee combs were spotty like appearance contained dead larvae which were brown in color and slimy in consistency. Some cells contained dried brown scales. The wax capping became sunken and irregularly perforated. Some cell caps became darker in color than other cells and the infected combs had a foul odor Fig.1. 


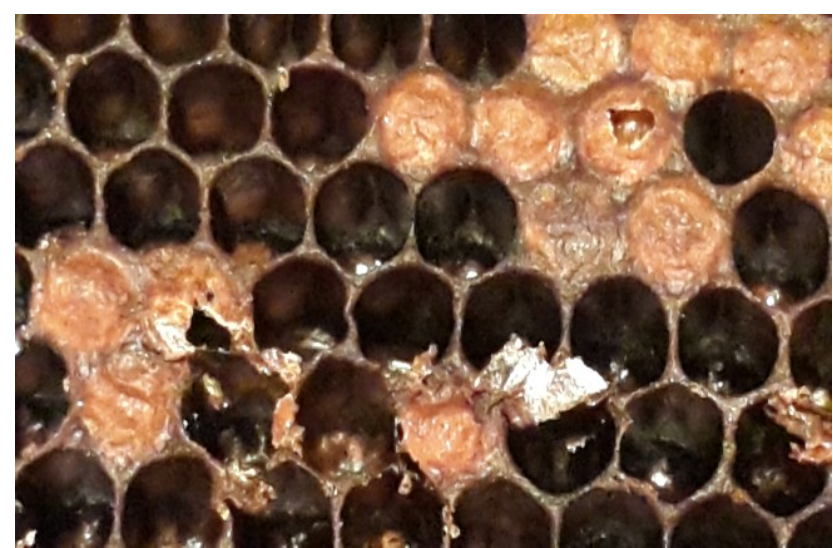

Fig.1. Bee comb contains irregular pattern of brood with perforatedand sunken caps.

\section{Isolation}

Three to five dead larvae were selected from each comb sample and placed in a test tube containing $5 \mathrm{ml}$ of sterile physiological saline $(0.85 \%$ of $\mathrm{NaCl})$ and homogenized to obtain suspension. The suspension was placed in water bath at $80 \mathrm{C}^{\circ}$ for 10-15 minutes to kill the spores of fungi and non-spore forming bacteria according to the method described by Kilic and Co-workers [6]. After cooling down the suspension, the tubes were stirred by vortex and a loopfull of the mixture was cultured on Columbia blood agar (Oxoid) and incubated at $37 \mathrm{C}^{\circ}$ for 3-5 days under $5-10 \%$ of $\mathrm{CO}_{2}$ using candle jar technique.

\section{- Identification of Paenibacillus larvae}

The following tests were used

- Colony morphology

- $\quad$ Bacterial morphology by Gram stain

- $\quad$ Biochemical reactions like Catalase, Indole, Methyl Red, Voges-Proskauer and Nitrate reduction tests.

- Motility test.

\section{Bacterial colony morphology}

\section{Results}

Colonies varied in size some were large while other were small about 1-2 mm in diameters, round with entire edge and smooth glistening with dark brown in color as shown in Fig. 2.

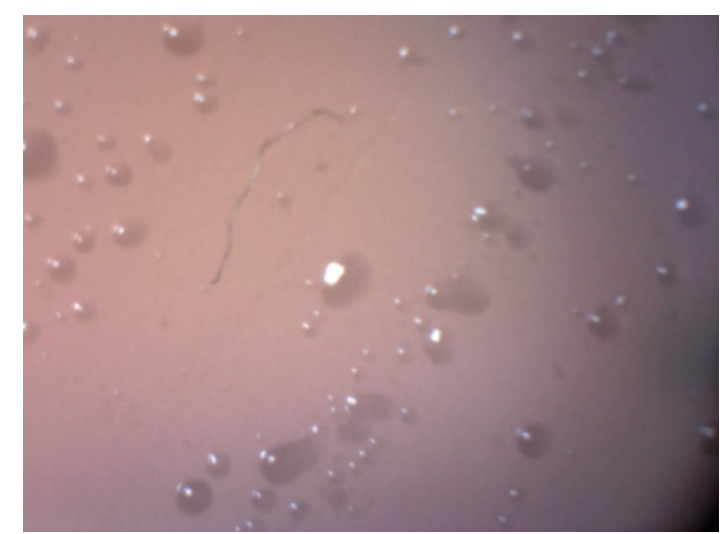

Fig.2. Isolated colonies of bacteria were variable in size, round, dark brown in color.

\section{Bacterial morphology}

Gram stained smear from isolated bacterial colonies revealed Gram positive bacilli arranged in single and chains as shown in Fig. 3. 


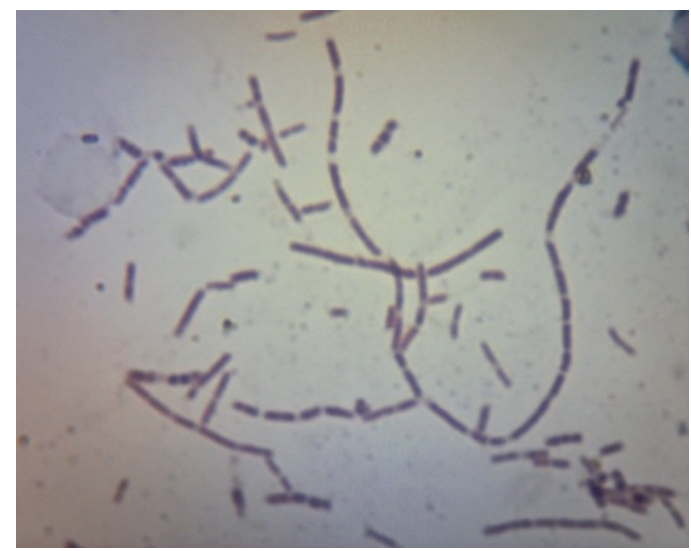

Fig.3. Gram positive bacilli arranged singly and in chains.

\section{Motility test}

All isolates were motile using hanging drop technique and inoculation to the semi-solid media.

\section{Biochemical reactions}

All isolates were positive for methyl red and nitrate reduction tests; whereas negative for catalase, Indole and Voges-Proskauer tests. According to the bacterial colony morphology, bacterial morphology, motility test and biochemical reactions the isolated strains were identified as Paenibacillus larvae.

Paenibacillus larvae was detected in $13(16.2 \%)$ samples among 80 suspected honey bee combs collected from apiaries of seven districts of Duhok province as shown in Table 1. Panebacillus larvae was detected in 5 from 7 districts in which the highest percentage (33.33\%) was isolated from samples collected from Zakho district which located at the border with Turkey.

Table.1.Paenibacillus larvae detected in the suspected honey bee combs

\begin{tabular}{|l|l|l|}
\hline District & Number of samples & Number (\%) of positive samples for P. larvae \\
\hline Duhok & 15 & $4(26.66 \%)$ \\
\hline Zakho & 12 & $4(33.33 \%)$ \\
\hline Sumel & 12 & $1(8.33 \%)$ \\
\hline Amedi & 14 & $3(21.42 \%)$ \\
\hline Aqre & 8 & 0 \\
\hline Shexan & 12 & $1(8.33 \%)$ \\
\hline Bardarash & 7 & 0 \\
\hline Total & 80 & $13(16.2 \%)$ \\
\hline
\end{tabular}

\section{Discussion}

American foulbrood disease (AFB) is the most infectious bacterial disease affects the larval stage of the honey bee Apis mellifera and occurs throughout the world wherever bees found. Paenibacillus larvae, the causative agent of AFB was isolated from $13(16.2 \%)$ infected samples among 80 suspected bee combs particularly those showing the typical gross pathological symptoms of the disease. The rate of infection in this study was more than those recorded by Abass and Co-workers [7] who found $2.12 \%$ of $P$. larvae in the infected bee frames collected from middle provinces of Iraq. This difference can be attributed to the methodology used, number of analyzed samples, time of sampling, geographical variation. This high rate of infection found in our area which located at the north of Iraq can be attributed to the illegal entrance of bee colonies from the neighbor countries as well as the ignorance of beekeepers about the ways of spreading of the disease. While the results agreed with those recorded by researchers in other parts of the world like Kauko and Niskanen[8] who found $17 \%$ of the rate of infection, Niskanen and Co-worker [9] found 20\%, Ayden and co-workers [10] found 13.6\%, Hornitzky and Clark [5] found 12.5-16.5\% and Akmaz[11] found 21.6\%.

This is the first study to be carried out and record the disease in the apiaries of Duhok province which suffered from severe losses during this year which reached $100 \%$ mortality rate.

\section{Conclusion}

American foulbrood disease is wide spread in the apiaries of Duhok Province and requires beekeepers awareness of the routes of transmission and methods of prophylaxis. 


\section{References}

[1]. E Genersch, E. Forsgren, J. Pentikainen, A. Ashiralieve, S. Rauch, J. Kilwinski,and I. Fries, Reclassification of panaebacillus larvae subsp. pulvifaciens and Paenibacilluslarvae subsp. larvae as Paenaebacilluswithout Subspecies differentiation, International Journal of Systemic and Evolutionary Microbiology, 56, 2006, 501-511.

[2]. D.C de Graaf, A.M. Alippi, M. Brown, J.D. Evans, M. Feldlaufer, A. Gregorc, M. Hornitzky, S.F. Perral, D.M.T. Schauch, D. Titera, V. Tomkies, and W. Ritter, Diagnosis of American foulbrood in honey bees: a synthetic and proposed analytical protocols, Letters in Applied Microbiology, 43, 2006, 583-590.

[3]. F.L.W Ratnieks, and D.A. Knox, Diagnosis of honey bee diseases, United State Department of agriculture, Washington DC, USA, 1991.

[4]. From internet: www.oie.int/terresterial Manual 2008.

[5]. M.A.Z Hornitzhy, and S. Clark, culture of Bacillus larvae from bulk honey samples for the detection of American foulbrood, Journal of Apicultural Researches, 30 (1), 1991, 13-16.

[6]. A Kilic, H, Simsik, and H. Kalender, Dtection of American Foulbrood Disease (Paenibacillus larvae) By the PCR and Culture, KafkasUniv Vet FakDerg, 16(5), 2010, 841-845.

[7]. A.SAbass, K.W. Shaher, R.S. Al-Jorany, The abundance of American Foulbrood Paenibacillus larvae and European Foulbrood Melissococcuspluto on the honey bees colonies in the middle of Iraq, Al-Anbar Journal for agricultural sciences, 8(4), 2010, 425437.

[8]. LKauko, and M. Niskanen, Occurance and diagnosis of American foulbrood in SW Finland, Sectio DD Med Vet, 50(825), 1995, 249253.

[9]. M Niskanen, L. Kauko, and T. Johansson, Detection of Bacillus larvae in honey by means of bovine blood agar, SoumenElainlaakarilehti, 101(2), 1995,73-78.

[10]. N Aydin, H. Bulbul, B. Biyikoglu, C. Yarali, and M.K. Yavus, KovanlardanvetuketimesunulanbalorneklerindenPaenibacillus larvaeninizolasyonu, Etlik Vet MicrobDerg, 10(11), 1997, 93-100.

[11]. O Akmaz, AdanaYoresindeAmerikanYavrucuruklugohastaligiinyaygginligi, Pendik Veterinary Microbiology Derg, 32(1-2), 2001, 55-61. 